\title{
Use of atypical antipsychotics in the elderly: a clinical review
}

\author{
This article was published in the following Dove Press journal: \\ Clinical Interventions in Aging \\ 16 August 2014 \\ Number of times this article has been viewed
}

\author{
Pietro Gareri' \\ Cristina Segura-García ${ }^{2}$ \\ Valeria Graziella Laura \\ Manfredi' \\ Antonella Bruni² \\ Paola Ciambrone ${ }^{2}$ \\ Gregorio Cerminara² \\ Giovambattista De Sarro² \\ Pasquale De Fazio \\ 'Elderly Health Care, Azienda \\ Sanitaria Provinciale Catanzaro, \\ Catanzaro, Italy; ${ }^{2}$ Department of \\ Health Sciences, University "Magna \\ Græcia” of Catanzaro, Catanzaro, Italy
}

Correspondence: Pasquale De Fazio Department of Health Sciences, University “Magna Græcia”, Campus Universitario Salvatore Venuta, Viale Europa, 88I00 Catanzaro, Italy

Tel +39961712393

Fax $+3996 \mid 712393$

Email defazio@unicz.it

\begin{abstract}
The use of atypical antipsychotic drugs in the elderly has become wider and wider in recent years; in fact, these agents have novel receptor binding profiles, good efficacy with regard to negative symptoms, and reduced extrapyramidal symptoms. However, in recent years, the use of both conventional and atypical antipsychotics has been widely debated for concerns about their safety in elderly patients affected with dementia and the possible risks for stroke and sudden death. A MEDLINE search was made using the words elderly, atypical antipsychotics, use, schizophrenia, psychosis, mood disorders, dementia, behavioral disorders, and adverse events. Some personal studies were also considered. This paper reports the receptor binding profiles and the main mechanism of action of these drugs, together with their main use in psychiatry and the possible adverse events in elderly people.
\end{abstract}

Keywords: atypical antipsychotics, dementia, elderly, psychosis, mood disorders, side effects

\section{Introduction}

Antipsychotics are among the most effective drugs used in psychiatry in the maintenance therapy of schizophrenia, in mania, or in acute psychotic reactions. ${ }^{1}$ In several other indications, such as delusional disorders, borderline psychoses, neurological conditions, or behavioral disturbances, clinical studies have been less comprehensive and often limited to particular antipsychotics, although results seemed to be positive in terms of remarkable improvement of patients. The use of conventional antipsychotics in the elderly is strongly limited by severe and intolerable side effects. ${ }^{2}$ In fact, conventional antipsychotics are $\mathrm{D}_{2}$ receptor antagonists and inhibit dopaminergic neurotransmission in a dose-related manner, whereas atypical agents cause serotonin and dopamine $\mathrm{D}_{2}$ receptor antagonism..$^{3-5}$ The use of atypical antipsychotic drugs in the elderly has become wider and wider in recent years; in fact, these agents have novel receptor binding profiles, good efficacy regarding negative symptoms, and few adverse effects, particularly in terms of reduced extrapyramidal symptoms (EPS). However, in recent years, the use of antipsychotics has been widely debated for concerns about safety in elderly patients affected with dementia and the possible risks for stroke and sudden death. ${ }^{6,7}$

This contribution is a clinical review based on the main characteristics of antipsychotic therapies in the elderly. It will focus on the characteristic binding profiles and the peculiar mechanism of action of these drugs, the side effects, and the potential risks of using atypical antipsychotics in light of the recent safety concerns in demented people. Then, it will describe the clinical use, and will also try to focus on the main characteristics that make these drugs useful.

This study, in fact, provides a practical guide to the use of this class of drugs in a particular population with several recurring medical comorbidities and the necessity of polypharmacotherapy. 


\section{Methods}

This review was a collaboration of two centers that normally participate in the integrated care of elderly patients with psychiatric disorders (Department of Health Sciences, University "Magna Græcia” of Catanzaro and Italy Elderly Health Care, Azienda Sanitaria Provinciale Catanzaro, Catanzaro, Italy).

The following scientific search engines were consulted: MEDLINE (through OvidSP; Wolters Kluwer, Alphen aan den Rijn, the Netherlands), CINAHL (through EBSCO; EBSCO Information Services, Ipswich, MA, USA), Embase (through Ovid; Wolters Kluwer), PsycINFO (through EBSCO), AgeLine, Cochrane Database of Systematic Reviews, and Database of Abstract of Reviews of Effects (DARE). Scientific websites introducing pertinent keywords were also searched. A secondary search was conducted on the references identified in the primary search.

The following terms were used: atypical antipsychotics, dementia, elderly, psychosis, mood disorders, and side effects. The inclusion criteria for the references include all relevant publications on the topic from 1994-2013, with particular attention on reviews. The studies were selected based on the following criteria of inclusion: no time limit and the results were considered generalizable. Studies with non-homogeneous samples were excluded.

This paper has been divided into specific sections. The Results section describes the pharmacodynamic aspects, adverse effects, possible interactions, and clinical use of this class of drugs in various pathological conditions. The Discussion section is about the clinical approach to the use of atypical antipsychotics, which takes into account the different guidelines, possible comorbidities, and the many practical problems in the treatment of elderly patients.

\section{Results}

\section{Receptor binding profiles of atypical antipsychotics}

Table 1 reports approximate receptor binding affinity expressed as equilibrium constant (ki)a of selected SGAs (amisulpride, aripiprazole, asenapine, clozapine, olanzapine, paliperidone, risperidone, quetiapine) and FGAs (sertindole, ziprasidone, haloperidol, perphenazine). Amisulpride is an alkylsulfone derivative of the substituted benzamide series of antipsychotics and presents a high affinity for presynaptic $\mathrm{D}_{2} / \mathrm{D}_{3}$ receptors, whereas it has no affinity for $\alpha_{1}$-adrenergic, histaminic, or cholinergic receptors. ${ }^{8-12}$ In particular, it shows antagonist properties toward $\mathrm{D}_{3}$ and both pre- and post-synaptic $\mathrm{D}_{2}$-like dopamine receptors of the rat striatum or nucleus accumbens in vitro. ${ }^{11}$
Doses between 400-1,200 mg/day are used for the treatment of psychosis by inhibition of dopaminergic neurotransmission, whereas low doses in the range of 50-200 mg preferentially block inhibitory presynaptic autoreceptors. This results in facilitation of dopamine activity, and for this reason lowdose amisulpride has also been used for treating dysthymia. Furthermore, it has recently been shown that amisulpride also acts as a potent 5-hydroxytryptamine $(\mathrm{HT})_{7}$ receptor antagonist. ${ }^{12}$ Several of the other atypical antipsychotics, such as risperidone and ziprasidone, are potent $5-\mathrm{HT}_{7}$ receptor antagonists as well, and selective antagonists of this receptor show antidepressant properties themselves. ${ }^{12}$

Clozapine is a dibenzodiazepine derivative with antidopaminergic and antiserotonergic activity but it also binds to $5-\mathrm{HT}_{2}, \alpha_{1}$, muscarinic, and histamine $(\mathrm{H})_{1}$ receptors. ${ }^{13-15} \mathrm{In}$ fact, it is included among the so-called multi-acting receptor-targeted antipsychotics (MARTA), together with olanzapine and quetiapine. Moreover, it binds more to $\mathrm{D}_{4}$ receptors than either $\mathrm{D}_{2}$ or $\mathrm{D}_{1}$ receptors. ${ }^{15}$ Furthermore, it has high affinity for serotonergic receptor subtypes $5-\mathrm{HT}_{2 \mathrm{~A}}, 5-\mathrm{HT}_{2 \mathrm{c}}$, and 5- $\mathrm{HT}_{3 \mathrm{c}}$, which may contribute to its antipsychotic properties and atypicality. ${ }^{16}$

Olanzapine is more potent as a 5-HT antagonist and presents lower potency at $\mathrm{D}_{1}, \mathrm{D}_{2}$, and $\alpha_{1}$ receptors. It also blocks $\mathrm{H}_{1}$ receptors and this explains its sedative properties. ${ }^{15}$ On the contrary, risperidone is a serotonin dopamine antagonist drug; first of all, it is equally potent in blocking $\mathrm{D}_{2}$ and 5-HT 2 receptors. Furthermore, its potency in blocking $\mathrm{D}_{2}$ receptors depends on the dose used. Increasing dosages of risperidone are able to proportionally block $\mathrm{D}_{2}$ receptors. This explains why risperidone may facilitate the onset of EPS in the elderly, especially at dosages superior to $2 \mathrm{mg} /$ day. ${ }^{10,13,17-19}$ Quetiapine is a lower potency compound with relatively similar antagonism of $5-\mathrm{HT}_{2}, \mathrm{D}_{2}, \alpha_{2}$, and $\alpha_{1}$ receptors. The $H_{1}$ receptor blockade is similar for clozapine, olanzapine, and quetiapine, and it is consistent with their sedative properties. ${ }^{10,13,20}$ Aripiprazole is a new antipsychotic agent with partial agonistic effects on $\mathrm{D}_{2}$ and $5-\mathrm{HT}_{1 \mathrm{~A}}$ receptors and antagonistic activity at 5- $\mathrm{HT}_{2 \mathrm{~A}}$ receptors. ${ }^{13,21,22}$ Ziprasidone has a high ratio of 5- $\mathrm{HT}_{2}$ receptor blockade to $\mathrm{D}_{2}$ receptor blockade; it is usually more effective in reducing psychotic symptoms and better tolerated than haloperidol, especially in movement disorders. ${ }^{13,22-24}$ Its weak anticholinergic effects show why it also has a more favorable cognitive profile than traditional agents in the elderly. Paliperidone is another new antipsychotic agent with a binding profile similar to that of risperidone. ${ }^{22,25}$ Recent studies have clearly shown that striatal receptor $\mathrm{D}_{2}$ occupancy, as measured by $\left({ }^{123} \mathrm{I}\right)$ iodobenzamide binding and single photon emission computerized tomography, may predict the occurrence of EPS 
Table I Receptor binding profiles and plasma half-life $\left(\mathrm{t}_{12}\right)$ of antipsychotic drugs

\begin{tabular}{|c|c|c|c|c|c|c|c|c|c|c|c|c|}
\hline \multirow{2}{*}{$\frac{\text { Drug class }}{\text { Receptor }}$} & \multicolumn{8}{|c|}{ Second-generation antipsychotics } & \multicolumn{4}{|c|}{ First-generation antipsychotics } \\
\hline & AMI & ARI & ASE & CLO & OLA & PALI & RIS & QUE & SER & ZIP & HAL & PER \\
\hline $\mathrm{D}_{2}$ & $1.3^{\mathrm{b}}$ & $0.66^{\mathrm{a}, \mathrm{b}}$ & $1.3^{\mathrm{b}}$ & 210 & 20 & 2.8 & 3.77 & 770 & 2.7 & 2.6 & 2.6 & $1.4^{\mathrm{b}}$ \\
\hline $5-\mathrm{HT}_{\text {IA }}$ & $>10,000^{c}$ & $5.5^{\mathrm{a}, \mathrm{b}}$ & $2.5^{\mathrm{b}}$ & 160 & 610 & 480 & 190 & 300 & 2,200 & $1.9^{\mathrm{a}, \mathrm{b}}$ & $\mathrm{I}, 800$ & 421 \\
\hline $5-\mathrm{HT}_{2 \mathrm{~A}}$ & $2,000^{c}$ & $8.7^{b}$ & $0.06^{\mathrm{b}}$ & 2.59 & 1.5 & 1.2 & 0.15 & 31 & 0.14 & 0.12 & 61 & $5^{b}$ \\
\hline $5-\mathrm{HT}_{2 \mathrm{C}}$ & $>10,000^{c}$ & $22^{\mathrm{b}}$ & $0.03^{b}$ & 4.8 & 4.1 & 48 & 32 & 3,500 & 6.0 & 0.9 & 4,700 & $132^{b}$ \\
\hline$\alpha_{1}$ & $7,100^{c}$ & $26^{b}$ & $1.2^{\mathrm{b}}$ & 6.8 & 44 & 10 & 2.7 & 8.1 & 3.9 & 2.6 & 17 & 10 \\
\hline$\alpha_{2}$ & $1,600^{c}$ & $74^{a}$ & $1.2^{\mathrm{b}}$ & 158 & 280 & 80 & 8 & 80 & 190 & 154 & 600 & 500 \\
\hline $\mathrm{H}_{1}$ & $>10,000^{d}$ & $30^{\mathrm{b}}$ & $1.0^{\mathrm{b}}$ & 3.1 & 0.08 & 3.4 & 5.2 & 19 & 440 & 4.6 & 260 & 8 \\
\hline$M_{1}$ & $\mathrm{~N} / \mathrm{A}$ & $6,780^{\mathrm{b}}$ & $8128^{b}$ & $1.4^{\mathrm{b}}$ & $2.5^{\mathrm{b}}$ & $>10,000^{b}$ & $>10,000^{b}$ & $120^{\mathrm{b}}$ & 5,000 & $300^{\mathrm{b}}$ & $>10,000^{b}$ & 1,500 \\
\hline$M_{2}$ & N/A & $3,510^{\mathrm{b}}$ & $4.5^{b}$ & $204^{b}$ & $622^{\mathrm{b}}$ & $>10,000^{b}$ & $>10,000^{b}$ & $630^{\mathrm{b}}$ & N/A & $>3,000^{\mathrm{b}}$ & $>10,000^{b}$ & N/A \\
\hline $\mathrm{M}_{3}$ & $\mathrm{~N} / \mathrm{A}$ & $4,680^{b}$ & $4.67^{b}$ & $109^{b}$ & $126^{\mathrm{b}}$ & $>10,000^{b}$ & $>10,000^{b}$ & $1,320^{\mathrm{b}}$ & $2,692^{b}$ & $>1,300^{b}$ & $>10,000^{b}$ & $\mathrm{I}, 848^{\mathrm{b}}$ \\
\hline$M_{4}$ & $\mathrm{~N} / \mathrm{A}$ & $1,520^{\mathrm{b}}$ & $5.09^{\mathrm{b}}$ & $27^{\mathrm{b}}$ & $350^{\mathrm{b}}$ & $>10,000^{b}$ & $>10,000^{b}$ & $660^{\mathrm{b}}$ & N/A & $>1,600^{b}$ & $>10,000^{b}$ & N/A \\
\hline
\end{tabular}

Notes: Adapted with permission from Correll CU, From receptor pharmacology to improved outcomes: individualizing the selection, dosing, and switching of antipsychotics, Eur Psychiatry, 2010;25(Suppl 2):SI2-S2I, Copyright () 2010, Elsevier Masson SAS. All rights reserved. ${ }^{79}$ Data represented as the equilibrium constant (Ki; nM), ie, nanomolar

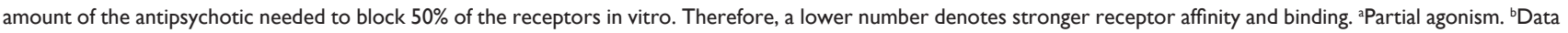
from cloned human brain receptors. 'Data extracted from rat. ${ }^{\mathrm{d} D}$ ata extracted from guinea pig.

Abbreviations: AMI, amisulpride; ARI, aripiprazole; ASE, asenapine; CLO, clozapine; HAL, haloperidol; OLA, olanzapine; PALI, paliperidone; PER, perphenazine; QUE, quetiapine; RIS, risperidone; SER, sertindole; ZIP, ziprasidone; N/A, not applicable.

in patients treated with atypical antipsychotics. ${ }^{26}$ Asenapine has a higher affinity for $5-\mathrm{HT}_{2 \mathrm{~A}}$ receptors than $\mathrm{D}_{2}$ receptors. ${ }^{27}$ Asenapine also has a high affinity for several other serotonin receptors, including $5-\mathrm{HT}_{2 \mathrm{C}}, 5-\mathrm{HT}_{7}, 5-\mathrm{HT}_{2 \mathrm{~B}}$, and $5-\mathrm{HT}_{6}$, in which it exerts antagonistic effects..$^{27}$ In addition, asenapine has demonstrated a high affinity for dopamine $\mathrm{D}_{3}, \mathrm{D}_{4}$, and $\mathrm{D}_{1}$ receptors, $\alpha_{1}$ - and $\alpha_{2}$-adrenergic receptors, and $\mathrm{H}_{1}$ receptors. It has moderate affinity for $\mathrm{H}_{2}$ receptors. ${ }^{27}$

The peculiar mechanism of action of atypical antipsychotics might be explained through the serotonin-dopamine interactions in the nigrostriatal, mesocortical, and tuberoinfundibular pathways. In fact, in the nigrostriatal pathway the atypical antipsychotic drug binds to the presynaptic $5-\mathrm{HT}_{2 \mathrm{~A}}$ receptor placed on a dopamine neuron. 5- $\mathrm{HT}_{2 \mathrm{~A}}$ antagonism is followed by dopamine release; therefore, there are usually no motor impairments or they are at a lower extent when compared to conventional antipsychotics. ${ }^{14}$ The same mechanism in the mesocortical pathway explains why atypical antipsychotics do not cause cognitive impairments; furthermore, 5- $\mathrm{HT}_{6}$ antagonism by olanzapine stimulates acetylcholine release. This action also improves cognitive functions. ${ }^{17}$ In the tuberoinfundibular pathway, dopamine inhibits and serotonin stimulates prolactin release; therefore, $5-\mathrm{HT}_{2 \mathrm{~A}}$ serotonin antagonism counteracts the effects of the $\mathrm{D}_{2}$ receptor blockade. ${ }^{5,10,13-14}$ However, at higher dosages, usually superior to $6 \mathrm{mg} /$ day, risperidone may cause endocrine side effects. ${ }^{10,17}$ This is often more evident in young people, especially women (ie, they can present amenorrhea or galactorrhea). In summary, this means that atypical antipsychotic drugs increase dopamine levels in the frontocortical and nigrostriatal pathways and cause a dramatic reduction of cognitive and motor impairments when compared to conventional antipsychotic drugs. On the other hand, atypical drugs reduce dopamine release in the mesocortical pathway, leading to antipsychotic effects. ${ }^{5,10,13,22}$ Moreover, atypical drugs transiently occupy $\mathrm{D}_{2}$ receptors and then rapidly dissociate to allow normal dopamine neurotransmission (hit and run mechanism). ${ }^{10}$ These characteristics make all the difference compared with conventional antipsychotic drugs in elderly people.

\section{Possible interactions, side effects, and risks in the use of atypical antipsychotics in elderly people}

Even if atypical antipsychotics have been potentially shown to cause serious cardiac and metabolic risks, they are still widely used. They became the top selling drug class in the US in 2008, edging out lipid regulator drugs and proton pump inhibitors. ${ }^{28}$

Table 2 reports the possible isoforms of cytochrome P450 (CYP) involved in atypical antipsychotic drugs metabolism. ${ }^{10,15}$ Drug substrates, inhibitors, and inducers are indicated too. Drug interactions might be relevant because the inhibition of some CYPs involved in atypical drug metabolism (CYP1A2, CYP3A4, CYP2D6, and CYP2C9) may lead to a number of side effects.

A study in $2005^{63}$ showed the possible relationship between the metabolic effects and treatment with atypical antipsychotics. It considered the pros and cons of the association between glucose or lipid dysregulation and eight separate second-generation antipsychotics currently available in the US and/or Europe: clozapine, olanzapine, risperidone, quetiapine, zotepine, amisulpride, ziprasidone, 
Table 2 Possible isoforms of CYP involved in atypical antipsychotic drugs metabolism

\begin{tabular}{|c|c|c|c|}
\hline Enzyme & Substrates & Inhibitors & Inductors \\
\hline \multirow[t]{5}{*}{ CYPIA2 } & Antipsychotics: clozapine,* olanzapine, asenapine, haloperidol & Ciprofloxacin & Barbiturates \\
\hline & Antidepressants: imipramine, amitriptyline, clomipramine, & Fluvoxamine & Carbamazepine \\
\hline & fluvoxamine, mirtazapine & & Phenytoin \\
\hline & Methylxanthines: theophylline, caffeine & & Rifampicin \\
\hline & Various drugs: paracetamol, R-warfarin, tacrine & & Tobacco \\
\hline \multirow[t]{9}{*}{ CYP3A4 } & Antipsychotics: clozapine, ${ }^{*}$ risperidone, ziprasidone, ${ }^{\wedge}$ sertindole, & Erythromycin & Barbiturates \\
\hline & quetiapine, aripiprazole, asenapine, haloperidol & Fluconazole & Carbamazepine \\
\hline & Antidepressants: venlafaxine, clomipramine, citalopram, mirtazapine & Fluvoxamine & Felbamate $\#$ \\
\hline & Benzodiazepines: diazepam, bromazepam & Grapefruit juice & Hypericum \\
\hline & Non-benzodiazepine anxiolytics: buspirone & Itraconazole & Oxcarbazepine ${ }^{\#}$ \\
\hline & Antiepileptics: carbamazepine, felbamate, tiagabine & Ketoconazole & Phenytoin \\
\hline & Calcium antagonists: nifedipine, diltiazem, verapamil & Nefazodone & Rifampicin \\
\hline & Various drugs: terfenadine, astemizole, cyclosporine, erythromycin, & & Topiramate ${ }^{\#}$ \\
\hline & clarithromycin, tamoxifen, amiodarone, quinidine & & \\
\hline \multirow[t]{9}{*}{ CYP2D6 } & Antipsychotics: risperidone, clozapine, olanzapine, aripiprazole, asenapine & Asenapine $^{\circ}$ & No known agent \\
\hline & zuclopenthixol, haloperidol, thioridazine, perphenazine, fluphenazine & Fluoxetine & \\
\hline & Antidepressants: amitriptyline, clomipramine, imipramine, desipramine, & Paroxetine & \\
\hline & fluvoxamine, nortriptyline, fluoxetine, paroxetine, fluvoxamine, & Perphenazine & \\
\hline & citalopram, venlafaxine, mirtazapine, mianserin & Propafenone & \\
\hline & Opioids: codeine, dextromethorphan, tramadol & Quinidine & \\
\hline & $\beta$-blockers: metoprolol, timolol, pindolol, propranolol & Thioridazine & \\
\hline & Antiarrhythmics: encainide, flecainide, propafenone & & \\
\hline & Various drugs: debrisoquine, sparteine, phenformin & & \\
\hline
\end{tabular}

Notes: *Also metabolized via CYP2C19. ^Also metabolized via aldehyde oxidase. ${ }^{\circ}$ Weak inhibitor. \#Weak enzymatic inductors. Abbreviation: CYP, cytochrome P450.

and aripiprazole. Further evidence about a variety of human populations, including some recent confirmatory evidence in treated psychiatric patients, shows that increased adiposity is associated with a variety of adverse physiological effects, including decreases in insulin sensitivity and changes in plasma glucose and lipid levels. Clozapine and olanzapine treatment are associated with the greatest risk of clinically significant weight gain, whereas other agents exhibit relatively lower levels of risk. ${ }^{17}$ On the contrary, risperidone, quetiapine, amisulpride, and zotepine show low-to-moderate levels of mean weight gain and a modest risk of clinically significant increases in weight. These studies show that clozapine and olanzapine treatment are associated with an increased risk for treatment-induced diabetes mellitus and dyslipidemia during risperidone treatment. ${ }^{17,63}$ Another recent paper ${ }^{64}$ made an association between the use of antipsychotic agents and the risk of acute myocardial infarction. In this study of a retrospective cohort of community-dwelling old patients who initiated cholinesterase inhibitor treatment, all new antipsychotics users during the length of the study were matched with a random sample of antipsychotics nonusers. Antipsychotics use was associated with a modest and timelimited increase risk for myocardial infarction.

Amisulpride has a low occurrence of EPS because of its preferential binding to dopamine receptors in extrastriatal regions rather than in the striatum. ${ }^{9-14}$
Trials with risperidone and olanzapine in elderly patients affected with dementia-related psychoses suggested the first warnings about the possible increase in cerebrovascular adverse events. ${ }^{6,17}$ The Committee on Safety of Medicines highlighted a three-fold increased risk of cerebrovascular events in elderly demented people who were treated with either risperidone or olanzapine in March 2004. ${ }^{65}$ In April 2005, another warning by the US Food and Drug Administration informed health professionals about the results of 17 randomized controlled trials, reporting a 1.7 times increased risk of all-cause mortality associated with antipsychotics use in elderly people affected with dementia. ${ }^{66} \mathrm{In}$ June 2008, the Food and Drug Administration also extended this warning to conventional antipsychotics. ${ }^{67}$ Since 2005 , a lot of papers have been published on this matter, with opposing conclusions; the debate in the scientific world still remains intense. However, drug regulatory agencies (US Food and Drug Administration, European Medicine Agency, and Commissione Unica del Farmaco) have issued specific recommendations and underline that treatment of behavioral and psychotic disorders in dementia with atypical antipsychotics is off-label. ${ }^{66,67}$ Furthermore, several studies showed that both conventional and atypical antipsychotic drugs are associated with an increased risk of all-cause mortality and sudden death compared to nonuse. ${ }^{7,43,68}$ The risk of pneumonia is higher in patients treated with antipsychotics, 
probably due to their anticholinergic and $\mathrm{H}_{1}$ receptor blocking actions, possibly causing swallowing problems and aspiration pneumonia. ${ }^{69}$ Deep venous thrombosis has also been described in patients taking both conventional and atypical antipsychotics. $^{70,71}$

Antipsychotic drugs-related QTc prolongation is a potential risk for developing life-threatening arrhythmias. The risk is higher when QTc is superior to 0.45 seconds $^{72}$ and following thioridazine and ziprasidone use. ${ }^{73}$ A midrange QT prolongation occurs following chlorpromazine and quetiapine use and a low range QT prolongation occurs following haloperidol, clozapine, risperidone, olanzapine, and aripiprazole use. ${ }^{73,74}$ Drug interactions with antipsychotics potentially increase the risk of adverse events, including QTc prolongation. ${ }^{75}$

Hypotension is a common adverse effect encountered with atypical drugs, especially following clozapine $(9 \%)$, quetiapine $(7 \%)$, risperidone, and olanzapine $(5 \%)$ use. ${ }^{2}$ Orthostatic hypotension has a high prevalence in the elderly, and drugs are often responsible - even psychotropics such as antipsychotics and antidepressants. A recent review in 2013 suggests that it is useful to identify specific molecules that, in combination with cardiovascular drugs, can cause orthostatic hypotension, in order to prevent it and avoid the associated complications. ${ }^{81}$
In elderly patients with bipolar disorder, peripheral edema and rash have been found after 14 days of treatment with asenapine. In all patients in whom such adverse events occurred, the discontinuity of treatment caused the rapid resolution of the event. In some cases, moderate sedation has been reported. ${ }^{78}$

Finally, changes in blood count may occur following antipsychotic drug use. Clozapine is known to induce neutropenia as well as agranulocytosis. ${ }^{10,15}$ Some cases of olanzapine, quetiapine, and risperidone-induced neutropenia and agranulocytosis have also been reported. ${ }^{76,77}$

Table 3 summarizes the possible side effects associated with atypical antipsychotics. . $^{810,13,15,17,19,20,24,25}$

\section{Clinical use of atypical antipsychotics in the elderly}

The use of atypical antipsychotics is reasonable in the management of acute symptoms (such as sudden onset or complications of preexisting clinical conditions) or in the long-term treatment of a specific kind of disease. In the first case, the choice of the antipsychotic drug is linked to the characteristics of the patient, to his/her general medical conditions, and to the severity of symptoms. Careful assessment of risks and benefits is requested.

In the second case, the therapeutic approach has to take into account the specific efficacy of each antipsychotic

Table 3 Side effects associated with atypical antipsychotics

\begin{tabular}{|c|c|c|c|c|c|c|c|c|c|}
\hline Side effects & $\begin{array}{l}\frac{0}{\frac{0}{2}} \\
\frac{\underline{0}}{\bar{z}} \\
\frac{\underline{n}}{\varepsilon} \\
\frac{\varepsilon}{4}\end{array}$ & $\begin{array}{l}\stackrel{0}{.} \\
\stackrel{\overline{0}}{\mathrm{~N}} \\
\text { N } \\
\frac{0}{U}\end{array}$ & $\begin{array}{l}0 \\
\frac{0}{0} \\
\frac{0}{2} \\
\frac{0}{0} \\
\frac{0}{n} \\
\frac{0}{\alpha}\end{array}$ & 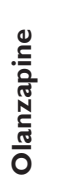 & 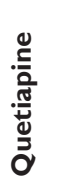 & $\begin{array}{l}\frac{0}{0} \\
\frac{0}{0} \\
\frac{0}{y} \\
\frac{0}{N}\end{array}$ & $\begin{array}{l}\frac{0}{0} \\
\text { N } \\
\frac{0}{2} \\
\frac{0}{2} \\
\frac{2}{4}\end{array}$ & 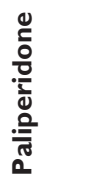 & 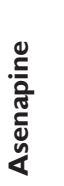 \\
\hline EPS & $-1+$ & - & $-1++$ & $-1+$ & - & $-1+$ & $-1+$ & $-1++$ & + \\
\hline Tardive dyskinesia & + & - & $?$ & $-1+$ & $-1+$ & $?$ & $-1+$ & $?$ & $-1+$ \\
\hline Seizures & - & +++ & $?$ & $-1+$ & $-1+$ & $?$ & $-1+$ & $?$ & $-1+$ \\
\hline Sedation & ++ & +++ & + & + & + & $?$ & $-1+$ & + & + \\
\hline NMS & + & + & + & $?$ & $?$ & $?$ & $?$ & + & $?$ \\
\hline Hypotension & + & $-1++$ & + & + & +++ & $-1+$ & $-1+$ & $-1++$ & $-1++$ \\
\hline QTc & $-1+$ & - & $-1+$ & - & +++ & $-1+$ & - & $-1+$ & $-1+$ \\
\hline $\begin{array}{l}\text { Gastrointestinal (nausea, } \\
\text { vomiting, constipation) }\end{array}$ & $-1+$ & $-1+$ & $-1+$ & - & + & $-1+$ & - & $-1+$ & - \\
\hline Anticholinergic & - & +++ & - & + & + & $-1+$ & - & - & - \\
\hline Hematological & - & +++ & - & - & - & - & - & - & - \\
\hline Other effects & $-1+$ & $-1+*$ & $-1+$ & $-1+$ & $-1+$ & $-1+$ & $-1+$ & $-1+$ & $-1+$ \\
\hline Diabetes & - & + & $-1+$ & $+?$ & - & - & - & $-1+$ & $-1+$ \\
\hline Hypertriglyceridemia & - & + & $-1+$ & + & - & - & - & $-1+$ & $-1+$ \\
\hline Hepatic & $-1+$ & $-1+$ & $-1+$ & $-1+$ & $-1+$ & $-1+$ & - & $-1+$ & + \\
\hline Prolactin increase & + & - & $-1++^{\wedge}$ & - & - & - & $-1+$ & $-1++^{\wedge}$ & $-1+$ \\
\hline Weight gain & $-1+$ & +++ & + & ++ & ++ & $-1+$ & - & + & + \\
\hline
\end{tabular}

Notes: *Polyserositis, acute interstitial nephritis, increased occurrence of infections, myocarditis; ^dosage dependent; - indicates no effect; + indicates mild effect; $-/+$ indicates uncertain effect; $-/++$ indicates probable dosage-dependent effect; ++ indicates moderate effect; +++ indicates severe effect; ? indicates no conclusive evidence.

Abbreviations: EPS, extrapyramidal symptoms; NMS, neuroleptic malignant syndrome; QTc, corrected QT. 
drug in the different diseases occurring among the elderly population.

\section{Schizophrenia}

A number of studies focused on the specific drugs used for the treatment of psychotic disturbances in the elderly. For example, amisulpride may improve negative symptoms; dosages larger than $600 \mathrm{mg}$ /day have antidopaminergic activity and are used in the treatment of acute delusional attacks and/or positive psychotic symptoms. ${ }^{11,31}$

Risperidone is also commonly used in the treatment of psychotic disorders in the elderly; the long-acting form of risperidone is also well tolerated and safe in the psychosis of the elderly and it could represent a good chance for those patients with dysphagia. In any case, these patients should start with oral consumption (from $0.5-3 \mathrm{mg} /$ day) to ascertain tolerability before the long-acting administration. ${ }^{32,33}$ It has been shown to be safe and effective in elderly patients with schizophrenia and schizoaffective disorders. Furthermore, its positive effects on cognition are probably due to the lack of antimuscarinic activity. ${ }^{17,34}$

Olanzapine is safe in treating any age adult patients with schizophrenia. Madhusoodanan et al demonstrated the efficacy and safety of olanzapine (5-20 mg/day) in eleven elderly patients aged between $60-85$ years with schizophrenia or schizoaffective disorders; it is usually well tolerated even if some elderly patients, when compared to young adults, may have a six-fold higher prevalence of tardive dyskinesia when treated with olanzapine. ${ }^{1,35,36}$

Quetiapine is indicated in the treatment of psychotic and behavioral disorders; ${ }^{2,22,29}$ Madhusoodanan et al demonstrated its efficacy in elderly patients affected with schizophreniarelated psychotic symptoms, schizoaffective disorders, or bipolar disorder. ${ }^{37}$ This is an effective treatment for patients with Parkinson's disease; in fact, quetiapineinduced EPS were no more frequent than those observed with placebo. ${ }^{21,31,37}$ The use of quetiapine, however, is still controversial, as the studies showing its limited efficacy on psychotic symptomatology compared with placebo cannot be ignored. ${ }^{80}$

Ziprasidone can be used intramuscularly or orally in the treatment of acute psychosis and is effective on positive and negative symptoms. ${ }^{2,23,24}$ Probable neuroprotective effects of ziprasidone have been suggested after immunohistochemical studies in the subchronic treatment of experimental models. ${ }^{38}$

Aripiprazole may be effective for the treatment of a variety of psychiatric conditions in the elderly, such as psychosis due to schizophrenia, bipolar disorders, depression, Parkinson's disease, and dementia (off-label use). ${ }^{27,31,39}$ A-26 week study with 310 patients with chronic schizophrenia aged over 77 years old proved that aripiprazole $15 \mathrm{mg}$ /day versus placebo significantly reduced Positive and Negative Syndrome Scale score and prevented time to relapse. ${ }^{40}$ Madhusoodanan et $\mathrm{al}^{41}$ evaluated the use of aripiprazole in elderly schizophrenia or schizoaffective disorder through a retrospective analysis of patients (aged 62-86 years) previously treated with typical or atypical antipsychotics. Seven out of ten patients showed an improvement in both positive and negative symptoms, and four out of ten experienced remission of EPS after the use of aripiprazole. No QT elongation was observed at follow-up.

Paliperidone (9-hydroxyrisperidone, the chief active metabolite of risperidone) is a new antipsychotic drug for the treatment of schizophrenia; a double-blind, placebocontrolled study with 6-month open-label extension showed the safety and tolerability of oral paliperidone extended release tablets in 114 old patients (mean age 70 years). ${ }^{42}$

Clozapine is used in schizophrenia refractory to other medications and in bipolar disorders; it has been shown to be very effective at very low doses for the management of psychosis in elderly patients with Parkinson's disease, schizophrenia, and dementia (off-label use in dementia). ${ }^{10,15,29,43,44}$

The Expert Consensus Guidelines produced guidelines for the use of antipsychotics in elderly patients affected with schizophrenia. ${ }^{2,45}$ They suggest that risperidone between $1.25-3.25 \mathrm{mg} /$ day is the first-choice treatment for late-onset schizophrenia. Quetiapine (100-300 mg/day), olanzapine (7.5-15 mg/day), and aripiprazole (15-30 mg/day) are identified as second-choice drugs. There is no unanimous consensus for the use of clozapine and ziprasidone. Therapy should be monitored every 2 months when the patient is stable and every 3 months in the maintenance phase. Clozapine and olanzapine, as well as typical antipsychotics, should be avoided in cases of diabetes, dyslipidemia, or obesity. If the therapeutic choice forces the use of one of these drugs, some anthropometrical and metabolic parameters (ie, glycemia, blood pressure, abdominal fat, body mass index) should be closely monitored ${ }^{46}$ In particular for schizophrenia, regardless of the specific treatment planned, both the individual variability in the response to the antipsychotic drugs and the effects of age itself on disease progression must be taken into account. Comorbidities, poor compliance to treatment (discontinuity in taking medications and sudden stop), and high rates of adverse events may significantly influence the efficacy of the most common antipsychotics in this 
population. Antipsychotics treatment should be combined with psychosocial interventions for the correct management of these comorbidities. ${ }^{47}$ Along this line, a retrospective longitudinal research study performed on a large sample of 49,173 male veterans with schizophrenia analyzed the receipt by patients of eleven types of guideline-concordant care and the association of such care with survival. Schizophrenia was associated with at least four diseases; the most common were hypertension (43\%) and dyslipidemia (29\%). As expected, the mean survival time was lower in schizophrenic patients affected with more comorbidities. ${ }^{4}$

\section{Dementia and behavioral disorders}

In the case of elderly patients affected with dementia, every antipsychotic treatment must be prescribed at the lowest effective dosage and for the shortest period possible. The severity and frequency of symptoms and the global functioning and quality of life, as reported by caregivers, must be always monitored during treatment. ${ }^{17,18,48}$

Based on the results of the Clinical Antipsychotic Trials of Intervention Effectiveness - Alzheimer's Disease (CATIE$\mathrm{AD}$ ), the role of atypical antipsychotics in influencing cognitive performance in patients with Alzheimer's is still debated. Some trials show that risperidone reduces the Mini-Mental State Examination scores in a statistically significant way compared with placebo, which is not the case with olanzapine and quetiapine. On the contrary, other trials indicate that quetiapine and olanzapine are responsible for greater cognitive decline. The samples of individual clinical trials are not enough to determine whether the cognitive decline varies with antipsychotic use; however, this decline has been evident for all the molecules compared to placebo. ${ }^{34}$

Risperidone has been found to be very effective in the treatment of some behavioral disorders such as agitation, aggression, and wandering in patients with dementia (off-label use). ${ }^{10,17,29,49-51}$ Behavioral and psychological symptoms of dementia may be both the consequence of cognitive impairment and bipolar disorder comorbidity that of an existing bipolar diathesis, which change the clinical expression of dementia. ${ }^{52}$ Agitation often worsens some types of dementia and atypical antipsychotics are often effective, even if their use is off-label. A review performed in 2012 comparing the efficacy of off-label use of atypical antipsychotics in dementia suggested that olanzapine, aripiprazole, and risperidone have a moderate-to-high efficacy in agitation. ${ }^{53}$ Furthermore, risperidone is indicated in dementia and secondary psychoses.

Although the use of antipsychotics for dementia is offlabel, antipsychotics are probably the best option for short-term treatment (6-12 weeks) of severe, persistent, and resistant aggression. ${ }^{54}$ Serious adverse events are a major contraindication to long-term therapy, thus suggesting that dosage be decreased and treatment interrupted whenever sufficient control of behavioral symptoms has been obtained.

Acute onset of confusion and delusions often occur in elderly hospitalized patients and may be effectively treated with second-generation antipsychotics. On the contrary, haloperidol has long been considered the drug of choice for treating agitation and aggression. At present, olanzapine, quetiapine, and risperidone show the same efficacy profile in acute stages of disease, without inducing the neurological effects of haloperidol. Ziprasidone and aripiprazole require careful use in acute stages since they are associated with a higher risk of arrhythmias. ${ }^{55}$

The new atypical drug asenapine might be a promising alternative for treating behavioral and psychotic disorders in dementia thanks to its peculiar mechanism of action; however, at present, it is indicated in bipolar disorder, and no evidence of its effectiveness has been proven in elderly patients affected with dementia. ${ }^{53}$

At the moment, little data are available on the treatment of psychosis in Parkinson's disease. ${ }^{44}$ Clozapine and quetiapine are the first-choice antipsychotics in Parkinson's disease; however, as already seen, the use of clozapine is limited by the possible onset of severe adverse events, such as agranulocytosis and myocarditis. ${ }^{10,15}$

\section{Mood disorders}

Second-generation antipsychotics in monotherapy (off-label use) are mainly indicated for elderly patients with unipolar depression who exhibit psychotic symptoms, or in the case of conventional antidepressant treatment resistance.

Little data exist in the literature on this topic. Olanzapine has been associated with several antidepressants in the treatment of major depressive disorder with psychotic symptoms. Olanzapine-sertraline showed a higher rate of remission compared to olanzapine-placebo at 12 weeks ( $42 \%$ versus $24 \%$ ) in a heterogeneous age-related sample. ${ }^{56}$ Even when all patients showed high levels of triglycerides and cholesterol, weight gain and hyperglycemia typically occurred in younger patients.

The augmentation of antidepressant therapy with aripiprazole also proved to be effective in resistant depression. ${ }^{57,58}$ The add-on treatment with aripiprazole $5 \mathrm{mg}$ caused significant reductions in both depressive and maniacal symptoms in a group of 20 elderly patients affected with bipolar disorder type I who partially responded to former treatment with mood stabilizers. ${ }^{59}$ 
Table 4 Pharmacokinetic parameters of atypical antipsychotics

\begin{tabular}{|c|c|c|c|c|}
\hline Drugs & Bioavailability (\%) & Plasma half-life (hours) & Active metabolites & Dosage forms \\
\hline Amisulpride & 48 & $12-17$ & Yes & Capsules, tablets \\
\hline Aripiprazole & 87 & 48-68; dehydroaripiprazole: 46-75 & Yes & $\begin{array}{l}\text { Tablets, orally disintegrating tablets, } \\
\text { liquid solution }\end{array}$ \\
\hline Asenapine & 35 & $\begin{array}{l}24 \\
\text { In elderly patients approximately } \\
30 \% \text { higher than in younger adults. }\end{array}$ & Yes & Sublingual tablets \\
\hline Clozapine & $|2-8|$ & $\mathrm{II}-105$ & Yes & Tablets, orally disintegrating tablets \\
\hline Olanzapine & 80 & 20-70 & Yes & Tablets, orally disintegrating tablets \\
\hline $\begin{array}{l}\text { Paliperidone extended } \\
\text { release }\end{array}$ & 28 & 23 & No & Extended-release tablets \\
\hline Quetiapine & $5-13$ & 7 & Yes & Tablets, prolonged-release tablets \\
\hline Risperidone & 68 & $3-24$ & Yes & $\begin{array}{l}\text { Tablets, orally disintegrating tablets, } \\
\text { liquid solution }\end{array}$ \\
\hline Risperidone long-acting & & $72-144$ (3-6 days) & Yes & Long-acting injectable \\
\hline Ziprasidone & 59 & $4-10$ & No & Tablets, capsules \\
\hline
\end{tabular}

Monotherapy with quetiapine (400-800 mg/day) was shown to be remarkably effective on symptoms progression in adult/elderly bipolar disorder patients through a significant decrease in Young Mania Rating Scale scores. ${ }^{60}$

Even if late-onset bipolar disorder presents a less severe course in the acuteness of manic episodes and shows a higher incidence of neurological and medical conditions, nowadays the common treatment strategy follows the guidelines for the treatment of bipolar disorders that are designed for younger patients. ${ }^{61}$ Few studies are actually published on the global management of bipolar disorder in elderly patients. ${ }^{62}$ Asenapine is indicated for the treatment of moderate-to-severe manic episodes associated with bipolar I disorder in adults. ${ }^{53}$

Table 4 reports some pharmacokinetic parameters of atypical antipsychotics. ${ }^{10,13,14,22}$

Table 5 reports the mean recommended dosages ( $\mathrm{mg} /$ day) of some atypical antipsychotics in different diseases in the elderly (schizophrenia, Parkinson's disease, and Alzheimer's disease).

\section{Discussion}

Prescribing atypical antipsychotic drugs to elderly people is challenging due to the recent evidence of possible side effects; however, their rational use may improve the quality of life and functional status of elderly patients with neuropsychiatric diseases. These drugs are still often misused; the availability of databases with longitudinal electronic health records of millions of people presents the opportunity to improve the knowledge on the risks and benefits of atypical antipsychotics in community-dwelling elderly patients. ${ }^{28,29}$ Atypical antipsychotics have been on the market since the 1990s, starting with clozapine; they have been shown to be effective in the treatment of negative symptoms of schizophrenia, such as apathy and catatonia. Moreover, they have demonstrated lower risks of EPS compared to conventional antipsychotics. For this reason, their use has increased worldwide, particularly in elderly patients. ${ }^{10}$ The use of these drugs increased approximately five times between 1999-2002 in Italy ${ }^{30}$ and six times between 1997-2001 in the UK, mainly in the treatment of behavioral and psychotic disorders in dementia. ${ }^{28,29}$ The use of risperidone and olanzapine has also increased in the US since $1997 . .^{28}$ Other possible uses of these drugs in the elderly include psychosis, schizophrenia, bipolar disorder, and psychosis related to Parkinson's disease - each drug shows a peculiar profile of use in elderly people. The use

Table 5 Mean recommended dosages ( $\mathrm{mg} /$ day) of some atypical antipsychotics in different diseases in the elderly (schizophrenia, Parkinson's disease, and Alzheimer's disease)

\begin{tabular}{llll}
\hline Drugs & Schizophrenia & Parkinson's disease & Dementia (off-label use) \\
\hline Amisulpride & $200-400 \mathrm{mg}$ & Insufficient evidence & Little evidence 200-400 mg \\
Aripiprazole & $15-30 \mathrm{mg}$ & Little evidence 10-15 mg & Little evidence 10-15 mg \\
Clozapine & $50-150 \mathrm{mg}$ & $25-100 \mathrm{mg}$ & $25-100 \mathrm{mg}$ \\
Olanzapine & $10-20 \mathrm{mg}$ & $5-7.5 \mathrm{mg}$ & $5-7.5 \mathrm{mg}$ \\
Paliperidone extended release & $3-12 \mathrm{mg}$ & $3-6 \mathrm{mg}$ & $3-12 \mathrm{mg}$ \\
Quetiapine & $200-300 \mathrm{mg}$ & $25-200 \mathrm{mg}$ & $25-200 \mathrm{mg}$ \\
Risperidone & $2-3 \mathrm{mg}$ & $0.25-1 \mathrm{mg}$ & $0.25-2 \mathrm{mg}$ \\
\hline
\end{tabular}


of atypical antipsychotics in the elderly is reasonable in the management of acute symptoms (such as sudden onset or complications of preexisting clinical conditions) or in the long-term treatment of a specific kind of disease. Atypical antipsychotic drugs have also been shown to be effective in the long-term treatment of elderly patients with schizophrenia. For elderly patients with unipolar depression, secondgeneration antipsychotics in monotherapy (off-label use) are mainly indicated in the case of psychotic symptoms or conventional antidepressant treatment resistance.

Aripiprazole, quetiapine, and more recently asenapine have been shown to be effective in the treatment of the elderly with bipolar disorders. ${ }^{59-62}$

Although the treatment of behavioral disorders in dementia with antipsychotics is off-label, antipsychotics are probably the best option in the short-term treatment (6-12 weeks) of severe, persistent, and resistant aggression. ${ }^{54}$ Serious adverse events are a major contraindication to longterm therapy. ${ }^{75}$

In fact, elderly patients are at increased risk of adverse events due to atypical antipsychotic drugs because of age-related changes in pharmacokinetics and pharmacodynamics and current medical conditions, polypharmacy, and potential drug interactions. US Food and Drug Administration black box warnings have clearly shown the potential risks of their use (eg, cerebrovascular accidents, risk of sudden death). Furthermore, metabolic adverse events are extremely dangerous. They are probably linked to an increase in adiposity associated with a variety of adverse physiological effects, including a decrease in insulin sensitivity and changes in plasma glucose and lipid levels. Clozapine and olanzapine treatment is associated with the greatest risk of clinically significant weight gain. On the contrary, risperidone, quetiapine, amisulpride, and zotepine show low-to-moderate levels of mean weight gain and a modest risk of clinically significant increases in body weight. The use of antipsychotics was associated with a modest and time-limited increase in the risk of myocardial infarction among old demented patients treated with cholinesterase inhibitors. QTc prolongation and hypotension are related to the kind of antipsychotic drug, its dosage, and interactions with other drugs. ${ }^{75}$ Other potential risks, such as increased risk of pneumonia, deep venous thrombosis, and changes in blood count, have been reported. ${ }^{82}$

\section{Conclusion}

The use of atypical antipsychotics in the elderly requires an individual assessment, case by case; ${ }^{18}$ particular caution is recommended. ${ }^{19}$
This review has highlighted the need to conduct further studies to identify the best treatment option with reference to the association between antipsychotic drugs and other classes of drugs used frequently in the elderly. The gold standard of therapy should involve the greatest benefit at the lowest mortality rate.

Since they have shown to be superior to conventional antipsychotics, careful use of atypical antipsychotics in elderly patients is strictly recommended. Importantly:

- they must be prescribed at the lowest effective dosage and for the shortest period possible;

- a balance of the risks and benefits is closely required;

- patients need to be monitored; and

- in light of an ethical viewpoint to improve patient's quality of life, the use of atypical antipsychotics is justified considering the poor results of alternative treatments (other psychotropic drugs and psychotherapeutic and psychosocial interventions).

\section{Author contributions}

Gareri and De Fazio conceived and designed the research. All authors made a substantial contribution to the acquisition, analysis, and the interpretation of the data. All authors participated in drafting the review and all authors reviewed it critically, giving a final approval of the version of the article to be published, and can certify that no other individuals not listed as authors have made substantial contributions to the paper.

\section{Disclosure}

The authors report no conflicts of interest in this work.

\section{References}

1. Aarsland D, Larsen JP, Lim NG, Tandberg E. Olanzapine for psychosis in patients with Parkinson's disease with and without dementia. J Neuropsychiatry Clin Neurosci. 1999;11(3):392-394.

2. Alexopoulos GS, Streim J, Carpenter D, Docherty JP. Using antipsychotic agents in older patients. J Clin Psychiatry. 2004;65(Suppl 2):5-99.

3. Ashcroft DM, Frischer M, Lockett J, Chapman SR. Variations in prescribing atypical antipsychotic drugs in primary care: cross-sectional study. Pharmacoepidemiol Drug Saf. 2002;11(4):285-289.

4. Barak Y, Shamir E, Weizman R. Would a switch from typical antipsychotics to risperidone be beneficial for elderly schizophrenic patients? A naturalistic, long-term, retrospective, comparative study. J Clin Psychopharmacol. 2002;22(2):115-120.

5. Meltzer HY. The role of serotonin in antipsychotic drug action. Neuropsychopharmacology. 1999;21(Suppl 2):106S-115S.

6. Shin JY, Choi NK, Jung SY, Lee J, Kwon JS, Park BJ. Risk of ischemic stroke with the use of risperidone, quetiapine and olanzapine in elderly patients: a population-based, case-crossover study. J Psychopharmacol. 2013;27(7):638-644

7. Ray WA, Chung CP, Murray KT, Hall K, Stein CM. Atypical antipsychotic drugs and the risk of sudden cardiac death. $N$ Engl J Med. 2009; 360(3):225-235.

8. Wetzel H, Wiesner J, Hiemke C, Benkert O. Acute antagonism of dopamine $\mathrm{D}_{2}$-like receptors by amisulpride: effects on hormone secretion in healthy volunteers. J Psychiatr Res. 1994;28(5):461-473. 
9. Xiberas X, Martinot JL, Mallet L, et al. In vivo extrastriatal and striatal $\mathrm{D}_{2}$ dopamine receptor blockade by amisulpride in schizophrenia. JClin Psychopharmacol. 2001;21(2):207-214.

10. Gareri P, De Fazio P, Stilo M, Ferreri G, De Sarro G. Conventional and atypical antipsychotics in the elderly: a review. Clin Drug Investig. 2003;23(5):287-322.

11. Schoemaker H, Claustre Y, Fage D, et al. Neurochemical characteristics of amisulpride, an atypical dopamine $\mathrm{D}_{2} / \mathrm{D}_{3}$ receptor antagonist with both presynaptic and limbic selectivity. J Pharmacol Exp Ther. 1997;280(1):83-97.

12. Abbas AI, Hedlund PB, Huang XP, Tran TB, Meltzer HY, Roth BL. Amisulpride is a potent 5- $\mathrm{HT}_{7}$ antagonist: relevance for antidepressant actions in vivo. Psychopharmacology (Berl). 2009;205(1):119-128.

13. Seeman P. Atypical antipsychotics: mechanism of action. Can J Psychiatry. 2002;47(1):27-38.

14. Stahl SM. Antipsychotic polypharmacy, part 1: therapeutic option or dirty little secret? J Clin Psychiatry. 1999;60(7):425-426.

15. Gareri P, De Fazio P, Russo E, Marigliano N, De Fazio S, De Sarro G. The safety of clozapine in the elderly. Expert Opin Drug Saf. 2008;7(5): $525-538$.

16. Khan AJ, Preskorn SH. Examining concentration-dependent toxicity of clozapine: role of therapeutic drug monitoring. J Psychiatr Pract. 2005;11(5):289-301.

17. Deberdt W, Dysken MW, Rappaport SA, et al. Comparison of olanzapine and risperidone in the treatment of psychosis and associated behavioral disturbances in patients with dementia. Am J Geriatr Psychiatry. 2005;13(8):722-730.

18. Burke AD, Tariot PN. Atypical antipsychotics in the elderly: a review of therapeutic trends and clinical outcomes. Expert Opin Pharmacother. 2009;10(15):2407-2414.

19. Jeste DV, Blazer D, Casey D, et al. ACNP White Paper: update on use of antipsychotic drugs in elderly persons with dementia. Neuropsychopharmacology. 2008;33(5):957-970.

20. Green B. Focus on quetiapine. Curr Med Res Opin. 1999;15(3): $145-151$.

21. Kohen I, Lester PE, Lam S. Antipsychotic treatments for the elderly: efficacy and safety of aripiprazole. Neuropsychiatr Dis Treat. 2010;6: $47-58$.

22. Markowitz JS, Brown CS, Moore TR. Atypical antipsychotics. Part I: pharmacology, pharmacokinetics, and efficacy. Ann Pharmacother. 1999;33(1):73-85.

23. Brook S, Lucey JV, Gunn KP. Intramuscular ziprasidone compared with intramuscular haloperidol in the treatment of acute psychosis. $J$ Clin Psychiatry. 2000;61(12):933-941.

24. Kech PE Jr, McElroy SL, Arnold LM. Ziprasidone: a new atypical antipsychotic. Expert Opin Pharmacother. 2001;2(6):1033-1042.

25. Madhusoodanan S, Zaveri D. Paliperidone use in the elderly. Curr Drug Saf. 2010;5(2):149-152.

26. Tauscher J, Kufferle B, Asenbaum S, Tauscher-Wisniewski S, Kasper S. Striatal dopamine-2 receptor occupancy as measured with (123 I) iodobenzamide and SPECT predicted the occurrence of EPS in patients treated with atypical antipsychotics and haloperidol. Psychopharmacology (Berl). 2002;162(1):42-49.

27. Shahid M, Walker GB, Zorn SH, Wong EH. Asenapine: a novel psychopharmacologic agent with a unique human receptor signature. J Psychopharmacol. 2009;23(1):65-73.

28. Hermann RC, Yang D, Ettner SL, Marcus SC, Yoon C, Abraham M. Prescription of antipsychotic drugs by office-based physicians in the United States, 1989-1997. Psychiatr Serv. 2002;53(4):425-430.

29. Jeste DV, Eastham JH, Lohr JB. Treatment of behavioral disorders and psychosis. In: Salzman C, editor. Clinical Geriatric Psychopharmacology. Baltimore, MD: Williams and Wilkins; 1998:106-149.

30. Trifiro G, Spina E, Brignoli O, Sessa E, Caputi AP, Mazzaglia G. Antipsychotic prescribing pattern among Italian general practitioners: a population-based study during the years 1999-2002. Eur J Clin Pharmacol. 2005;61(1):47-53.
31. Crismon L, Argo TR, Buckley PF. Schizophrenia. In: DiPiro JT, Talbert RL, Yee GC, Matzke GR, Wells BG, Posey M, editors. Pharmacotherapy: A Pathophysiologic Approach. 7th ed. New York, NY: McGraw-Hill; 2008:1099-1123.

32. Singh D, O'Connor DW. Efficacy and safety of risperidone long-acting injection in elderly people with schizophrenia. Clin Interv Aging. 2009;4:351-355.

33. Davidson M, Harvey PD, Vervarcke J, et al. A long-term, multicenter, open-label study of risperidone in elderly patients with psychosis. Int J Geriatr Psychiatry. 2000;15(6):506-514.

34. Vigen CL, Mack WJ, Keefe RS, et al. Cognitive effects of atypical antipsychotic medications in patients with Alzheimer's disease: outcomes from CATIE-AD. Am J Psychiatry. 2011;168(8):831-839.

35. Madhusoodanan S, Sinha S, Brenner R, Gupta S, Bogunovic O. Use of olanzapine for elderly patients with psychotic disorders: a review. Ann Clin Psychiatry. 2001;13(4):201-213.

36. Solomos K, Geiger O. Olanzapine use in the elderly: a retrospective analysis. Can J Psychiatry. 2000;45(2):151-155.

37. Madhusoodanan S, Brenner R, Alcantra A. Clinical experience with quetiapine in elderly patients with psychotic disorders. J Geriatr Psychiatry Neurol. 2000;13(1):28-32.

38. Kam KY, Jalin AM, Choi YW, et al. Ziprasidone attenuates brain injury after focal cerebral ischemia induced by middle artery occlusion in rats. Prog Neuropsychopharmacol Biol Psychiatry. 2012;39(1):69-74.

39. Rado J, Janicak PG. Aripiprazole for late-life schizophrenia. Clin Interv Aging. 2010;5:253-258.

40. Pigott TA, Carson WH, Sara AR, et al. Aripiprazole for the prevention of relapse in stabilized patients with chronic schizophrenia: a placebo-controlled 26-week study. J Clin Psychiatry. 2003;64(9): 1048-1056.

41. Madhusoodanan S, Brenner R, Gupta S, Reddy H, Bogunovic O. Clinical experience with aripiprazole treatment in ten elderly patients with schizophrenia or schizoaffective disorder: retrospective case studies. CNS Spectr. 2004;9(11):862-867.

42. Tzimos A, Samokhvalov V, Kramer M, et al. Safety and tolerability of oral paliperidone extended-release tablets in elderly patients with schizophrenia: a double-blind, placebo-controlled study with 6-month open label extension. Am J Geriatr Psychiatry. 2008;16(1):31-43.

43. Jeste DV, Blazer D, Casey D, et al. ACNP White Paper: update on use of antipsychotic drugs in elderly persons with dementia. Neuropsychopharmacol. 2008;33(5):957-970.

44. Wolters EC, Berendse HW. Management of psychosis in Parkinson's disease. Curr Opin Neurol. 2001;14(4):499-504.

45. Tsan JY, Stock EM, Gonzalez JM, et al. Mortality and guidelineconcordant care for older patients with schizophrenia: a retrospective longitudinal study. BMC Med. 2012;10:147.

46. Felmet K, Zisook S, Kasckow JW. Elderly patients with schizophrenia and depression: diagnosis and treatment. Clin Schizophr Relat Psychoses. 2011;4(4):239-250.

47. Jeste DV, Maglione JE. Treating older adults with schizophrenia: challenges and opportunities. Schizophr Bull. 2013;39(5):966-968.

48. Kuehn BM. Questionable antipsychotic prescribing remains common, despite serious risks. JAMA. 2010;303(16):1582-1584.

49. Katz R, Jeste DV, Mintzer JE, Clyde C, Napolitano J, Brecher M. Comparison of risperidone and placebo for psychosis and behavioral disturbance associated with dementia: a randomized, double-blind trial. J Clin Psychiatry. 1999;60(2):107-115.

50. Lavretsky H, Sultzer D. A structured trial of risperidone for the treatment of agitation in dementia. Am J Geriatr Psychiatry. 1998;6(2): 127-135.

51. Gareri P, Marigliano NM, De Fazio S, et al. Antipsychotics and dementia. BMC Geriatr. 2010;10(Suppl 1):A93.

52. Dorey JM, Beauchet O, Thomas Antérion C, et al. Behavioral and psychological symptoms of dementia and bipolar spectrum disorders: review of the evidence of a relationship and treatment implications. CNS Spectr. 2008;13(9):796-803. 
53. Maher AR, Theodore G. Summary of the comparative effectiveness review on off-label use of atypical antipsychotics. J Manag Care Pharm. 2012;18(5 Suppl B):S1-S20.

54. Ballard CG, Gauthier S, Cummings JL, et al. Management of agitation and aggression associated with Alzheimer disease. Nat Rev Neurol. 2009;5(5):245-255.

55. Pelland C, Trudel JF. [Atypical antipsychotic efficacy and safety in managing delirium: a systematic review and critical analysis]. Psychol Neuropsychiatr Vieil. 2009;7(2):109-119. French.

56. Meyers BS, Flint AJ, Rothschild AH, et al. A double-blind randomized controlled trial of olanzapine plus sertraline vs olanzapine plus placebo for psychotic depression: the study of pharmacotherapy of psychotic depression (STOP-PD). Arch Gen Psychiatry. 2009;66(8):838-847.

57. Alexopoulos GS. Pharmacotherapy for late-life depression. J Clin Psychiatry. 2011;72(1):e04.

58. Berman RM, Fava M, Thase ME, et al. Aripiprazole augmentation in major depressive disorder: a double-blind, placebo-controlled study in patients with inadequate response to antidepressants. CNS Spectr. 2009;14(4):197-206.

59. Sajatovic M, Coconcea N, Ignacio RV, et al. Aripiprazole therapy in 20 older adults with bipolar disorder: a 12-week, open-label trial. J Clin Psychiatry. 2008;69(1):41-46.

60. Sajatovic M, Calabrese JR, Mullen J. Quetiapine for the treatment of bipolar mania in older adults. Bipolar Disord. 2008;10(6):662-671.

61. Vasudev A, Thomas A. "Bipolar disorder" in the elderly: what's in a name? Maturitas. 2010;66(3):231-235.

62. Aziz R, Lorberg B, Tampi RR. Treatments for late-life bipolar disorder. Am J Geriatr Pharmacother. 2006;4(4):347-364.

63. Newcomer J. Second-generation (atypical) antipsychotic and metabolic effects: a comprehensive literature review. CNS Drugs. 2005; 19(Suppl 1):1-93.

64. Pariente A, Fourrier-Reglat A, Ducruet T, et al. Antipsychotic use and myocardial infarction in older patients with treated dementia. Arch Intern Med. 2012;172(8):648-653.

65. Gill SS, Rochon PA, Herrmann N, et al. A typical antipsychotic drugs and risk of ischaemic stroke: population based retrospective cohort study. BMJ. 2005;330:445.

66. Citizens Commission on Human Rights. US Food and Drug Administration Warning on Antipsychotic Drugs. California: Citizens Commission on Human Rights; 2005. Available from: http://www.cchrint.org/pdfs/ US_Food_and_Drug_Administration_Warnings_on_Antipsychotic_ Drugs.pdf. Accessed August 05, 2014.

67. FDA requests boxed warnings on older class of antipsychotic drugs news release. Silver Spring, MD: US Food and Drug Administration; 2008 [updated June 16, 2008; cited June 24, 2008] Available from: www.fda.gov/NewsEvents/Newsroom/PressAnnouncements/2008/ ucm116912.htm. Accessed July 31, 2014.
68. Liperoti R, Onder G, Landi F, et al. All-cause mortality associated with atypical and conventional antipsychotics among nursing home residents with dementia: a retrospective cohort study. J Clin Psychiatry. 2009;70(10):1340-1347.

69. Trifiro G, Gambassi G, Sen EF, et al. Association of communityacquired pneumonia with antipsychotic drug use in elderly patients: a nested case-control study. Ann Intern Med. 2010;152(7):418-425.

70. Liperoti R, Pedone C, Lapane KL, Mor V, Bernabei R, Gambassi G. Venous thromboembolism among elderly patients treated with atypical and conventional antipsychotic agents. Arch Intern Med. 2005;165(22): 2677-2682.

71. Kleijer BC, Heerdink ER, Egberts TC, Jansen PA, van Marum RJ. Antipsychotic drug use and the risk of venous thromboembolism in elderly patients. J Clin Psychopharmacol. 2010;30(5):526-530.

72. Zareba W, Lin DA. Antipsychotic drugs and QT interval prolongation Psychiatr Q. 2003;74(3):291-306.

73. Glassman AH, Bigger JT Jr. Antipsychotic drugs: prolonged QTc interval, torsade de pointes, and sudden death. Am J Psychiatry. 2001;158(11):1774-1782.

74. Chung AK, Chua SE. Effects on prolongation of Bazett's corrected QT interval of seven second-generation antipsychotics in the treatment of schizophrenia: a meta-analysis. J Psychopharmacol. 2011;25(5): 646-666.

75. Gareri P, De Fazio P, Manfredi VG, De Sarro G. Use and safety of antipsychotics in behavioral disorders in elderly demented people. J Clin Psychopharmacol. 2014;34(1):109-123.

76. Rettenbacher MA, Hofer A, Kemmler G, Fleischhacker WW. Neutropenia induced by second generation antipsychotics: a prospective investigation. Pharmacopsychiatry. 2010;43(2):41-44.

77. Li X, Cameron MD. Potential role of a quetiapine metabolite in quetiapine-induced neutropenia and agranulocytosis. Chem Res Toxicol. 2012; 25(5):1004-1011.

78. Baruch Y, Tadger S, Plopski I, Barak Y. Asenapine for elderly bipolar manic patients. J Affect Disord. 2013;145(1):130-132.

79. Correll CU. From receptor pharmacology to improved outcomes: individualizing the selection, dosing, and switching of antipsychotics. Eur Psychiatry. 2010;25(Suppl 2):S12-S21.

80. Ondo WG, Tintner R, Voung KD, Lai D, Ringholz G. Double-blind, placebo-controlled, unforced titration parallel trial of quetiapine for dopaminergic-induced hallucinations in Parkinson's disease. Mov Disord. 2005;20(8):958-963.

81. Pepersack T, Gilles C, Petrovic M, et al. Prevalence of orthostatic hypotension and relationship with drug use amongst older patients. Acta Clin Belg. 2013;68(2):107-112.

82. Shulman M, Jennifer Njoku I, Manu P. Thrombotic complications of treatment with antipsychotic drugs. Minerva Med. 2013;104(2): $175-184$.
Clinical Interventions in Aging

\section{Publish your work in this journal}

Clinical Interventions in Aging is an international, peer-reviewed journal focusing on evidence-based reports on the value or lack thereof of treatments intended to prevent or delay the onset of maladaptive correlates of aging in human beings. This journal is indexed on PubMed Central, MedLine,

\section{Dovepress}

CAS, Scopus and the Elsevier Bibliographic databases. The manuscript management system is completely online and includes a very quick and fair peer-review system, which is all easy to use. Visit http://www.dovepress. com/testimonials.php to read real quotes from published authors. 